\title{
Single-incision laparoscopic cholecystectomy in a resource-poor setting: improving safety during the learning curve
}

\author{
Arpit Mathew $^{1}$, Lurstep Wanshnong ${ }^{2}$, Cornerstone Wann ${ }^{3}$
}

\author{
${ }^{1}$ Assistant Professor, Christian Medical College, Ludhiana, Punjab, India \\ ${ }^{2}$ Consultant Surgeon, Dr. H. Gordon Roberts Hospital, Shillong, Meghalaya, India \\ ${ }^{3}$ Department of Urology, Christian Medical College, Vellore, Tamil Nadu, India
}

Received: 19 November 2015

Revised: 17 December 2015

Accepted: 18 December 2015

\section{*Correspondence: \\ Dr. Arpit Jacob Mathew, \\ E-mail: ajmats@yahoo.co.in}

Copyright: () the author(s), publisher and licensee Medip Academy. This is an open-access article distributed under the terms of the Creative Commons Attribution Non-Commercial License, which permits unrestricted non-commercial use, distribution, and reproduction in any medium, provided the original work is properly cited

\begin{abstract}
Background: Single Incision Laparoscopic Cholecystectomy is becoming a widely performed operation with various techniques and special instruments having been developed for the procedure. However, these tend to increase the cost of the operation and hence are not always feasible options in smaller centres with poor patients. We describe a safe, low cost operation that involves the same equipment and instruments as the conventional laparoscopic cholecystectomy and draw conclusions on the steps to improve safety during the learning curve.

Methods: The study was conducted on 35 patients who underwent Single Incision Laparoscopic Cholecystectomy out of 212 who underwent laparoscopic cholecystectomy at a secondary level charitable hospital in Shillong, Meghalaya, India from November 2009 to March 2011.

Results: With careful case selection, single incision laparoscopic cholecystectomy was safely performed on 35 patients. 2 tall patients required an additional port in the epigastrium since the instruments were not long enough to comfortably reach the Calot's triangle. One patient developed a wound infection after 3 weeks and there were no other reported complications or incidence of hernia after 4 years.

Conclusions: With wise patient selection, proficiency in 3-port cholecystectomy, demonstration of the critical view of safety, proper placement of the ports and utilisation of standard laparoscopic instruments, single incision laparoscopic cholecystectomy can be safely performed without major complications and at no increased cost even in smaller hospitals without specialised training in the procedure.
\end{abstract}

Keywords: Single-incision laparoscopic cholecystectomy, Learning curve, Safe surgery

\section{INTRODUCTION}

Since the advent of diagnostic laparoscopy through the pioneering work of Hans Christian Jacobaeus and Georg Kelling in the early 1900 s, there has been great progress in the technology, skill as well as attitude towards laparoscopic procedures with laparoscopy having become the gold-standard procedure for many operations including cholecystectomy. Single Incision Laparoscopic Cholecystectomy (SIL) was first described in $1997 .{ }^{1}$
However, till date, the procedure is generally offered only in specialized centers due to the high costs of the equipment involved and technical difficulties. With the gradual increase in the acceptability of the procedure, innovative use of routine laparoscopic instruments has greatly reduced the cost of the procedure. ${ }^{1}$ Though it has been shown that there need be no increased cost compared to laparoscopic cholecystectomy, the procedure has not become a regular practice in most hospitals, although a few specialised centres do offer SIL as the 
standard procedure for all their elective cholecystectomies. ${ }^{1}$ In secondary level hospitals, it is often felt that such procedures are beyond the expertise and purview of the surgeons and facilities and are rarely performed. Moreover, without specialized training, the risk of complications often prevents this procedure from being adopted. In this article we study the adoption of low-cost single incision laparoscopy in a secondary-level hospital and draw conclusions on steps to improve safety during the learning curve.

\section{METHODS}

The study was conducted at a 365 bedded, secondary level charitable hospital in Meghalaya, India. Due to the fair skin of the people from Meghalaya, it was noticed that conventional laparoscopic cholecystectomy (CL) would often leave noticeable scars on the patients. In order to improve cosmesis, we initially began to perform 3 -port laparoscopic cholecystectomy and in November 2009, performed our first single incision laparoscopic cholecystectomy (SIL). During the period of this study from November 2009 till February 2011, there were 212 laparoscopic cholecystectomies of which 35 were done by the SIL procedure.

The SIL procedure involved making an incision in the umbilicus and placing a $10 \mathrm{~mm}$ metal port with a small head (Storz) via the standard open procedure. For the initial procedures the surgeon would stand between the legs of the patient, but due to the extra time taken for positioning, we then reverted back to the conventional supine position. The surgeon would stand closer to the legs of the patient and the assistant holding the camera would stand nearer the head-end to reduce clashing of instruments outside the abdomen. After insufflation of the abdomen, the telescope was inserted through a $10 \mathrm{~mm}$ port and the gall bladder was visualized. If there were dense adhesions of omentum or bowel to the gall bladder, the procedure was immediately converted to a standard 3port or 4-port laparoscopic cholecystectomy. If not, the umbilical incision was extended around the circumference of the umbilicus leaving a skin bridge superiorly and making sure the incision remained within the umbilicus. Another $10 \mathrm{~mm}$ port was placed at the right apex of the skin incision, but with the entry point in the rectus sheath about $6-9 \mathrm{~mm}$ above the first port just lateral to the midline. A $5 \mathrm{~mm}$ port was placed at the right apex of the incision with the entry point in the rectus right lateral to the midline. Hence the initial $10 \mathrm{~mm}$ port was below the other two ports and formed a triangle. The procedure was then carried out as for a standard laparoscopic cholecystectomy except that dissection in the Calot's triangle was carried out with a right angled forceps instead of the Maryland dissecting forceps as well as a hook cautery. In some cases when operative mobility and vision was restricted, a crossed hands approach, with the right hand retracting the gall bladder and the left hand dissecting with the hook cautery and the instruments crossing in the abdomen was found to be useful. Once the
Calot's triangle was dissected and the critical view of safety visualized, the cystic duct and artery were clipped through the lower $10 \mathrm{~mm}$ port. For 3 patients we used only a single $10 \mathrm{~mm}$ port and changed to a $5 \mathrm{~mm}$ scope during the clipping of the duct and artery. However, the optics was not ideal and this procedure was not continued. After freeing of the gall bladder from the liver bed, the gall bladder was removed using a plastic bag (improvised from the sterile plastic cover of a suction catheter) to minimize the risk of rupture of the gall bladder while removing it from the abdomen. The rectus incisions were closed individually with No.1 vicryl and the skin with 3.0 Nylon. The rectus defect of the $5 \mathrm{~mm}$ port was not closed.

\section{RESULTS}

Of the 177 patients who underwent conventional laparoscopic cholecystectomy, there were $13(7.3 \%)$ conversions to open cholecystectomy -8 for common bile duct stones (missed on ultrasound but identified by intra-operative cholangiogram), 4 for difficult anatomy and 1 for bleeding. Of the 35 patients who underwent SIL, 2 required an additional port in the epigastrium. Both patients were tall and we found that our instruments were not long enough to comfortably reach the Calot's triangle when the gall bladder was retracted upwards.

Table 1: Conventional laparoscopic cholecystectomy of patients.

\begin{tabular}{|lll|}
\hline & $\begin{array}{l}\text { Number } \\
\text { (Total) }\end{array}$ & $\begin{array}{l}\text { Percentage } \\
\%\end{array}$ \\
\hline $\begin{array}{l}\text { Number of conventional } \\
\text { laparoscopic } \\
\text { cholecystectomies (CL) }\end{array}$ & $\begin{array}{l}177 \\
(212)\end{array}$ & 83.5 \\
\hline $\begin{array}{l}\text { Conventional laparoscopic } \\
\text { cholecystetomy converted } \\
\text { to open }\end{array}$ & $13(177)$ & 7.3 \\
\hline $\begin{array}{l}\text { Number of single incision } \\
\text { laparoscopic } \\
\text { cholecystectomies (SIL) }\end{array}$ & $35(212)$ & 16.5 \\
\hline $\begin{array}{l}\text { SIL converted to open (out } \\
\text { of 35) }\end{array}$ & $0(35)$ & 0 \\
\hline $\begin{array}{l}\text { SIL requiring additional } \\
\text { port }\end{array}$ & $2(35)$ & 5.7 \\
\hline SIL with bile spillage & $3(35)$ & 8.6 \\
\hline $\begin{array}{l}\text { SIL requiring intra-op } \\
\text { cholangiogram (raised }\end{array}$ & $1(35)$ & 2.8 \\
ALP) & & \\
\hline $\begin{array}{l}\text { Post-op bile duct } \\
\text { complications/collection } \\
\text { (SIL) }\end{array}$ & $0(35)$ & 0 \\
\hline $\begin{array}{l}\text { Post-op wound infection } \\
\text { (SIL) }\end{array}$ & $1(35)$ & 2.8 \\
\hline Post-op hernia (SIL) & $0(35)$ & 0 \\
\hline
\end{tabular}

Two patients had bile spillage during the operation due to perforation of the gall bladder by the grasper in the left 
hand and one patient had bile spillage during removal of the gall bladder from the umbilical port. None of the patients required the placement of a drain. One patient

had a raised Alkaline Phosphatase with a normal sized common bile duct on pre-operative evaluation. An intraoperative cholangiogram was done, which was normal. The operating time reduced gradually from around 120 minutes for the first 10 cases to around 60 minutes by case 30 . One patient developed a wound infection after 3 weeks of the operation. She underwent a wound exploration under local anaesthesia in the out-patient and removal of the vicryl suture following which the infection settled with no development of a hernia. There were no other reported post-operative complications after four years. The salient results are tabulated in Table 1 .

\section{DISCUSSION}

Case selection was the major reason for the low conversion rate to $\mathrm{CL}$ and the minimal complications in our study. Any patient who had acute cholecystitis or a thickened gall bladder would be pre-operatively planned for CL. A review of 29 published articles on the procedure found that the success percentage of the operation dropped from $93 \%$ to $59.9 \%$ for patients with acute cholecystitis. It has also been noted that increased age and higher body body-mass index also contributed to lowering the success rates. In our study, if there were any adhesions or signs of acute inflammation noted on diagnostic laparoscopy, the procedure was immediately converted to CL. As a result, in the period of the learning curve, we were able to perfect the new skills required for SIL on relatively simpler operations. Even without special training in the procedure, by careful case selection, we were able to minimize complications.

In our series, we ensured visualization of Strasbergs critical view of safety before clipping or tying the cystic duct. This ensures that bile duct injuries are minimized although this increases the operating time, especially in single incision surgery, where medial dissection is often possible only with the crossed-hands technique.

The next important aspect in improving the safety of the learning curve was the comfort levels reached while operating with only 3 ports. This was due to the routine performance of 3-port laparoscopic cholecystectomy before transitioning to SIL. This also helped in alleviating the need for suture retraction of the fundus.

The placement of the ports was found to be the key factor in performing the operation easily and safely. We found that the distances between the ports needed to be neither too close nor too far to prevent clashing of the instruments while preserving cosmesis. A distance of about $1 \mathrm{~cm}$ was found to be ideal for ease of operating. We found that instead of going through the umbilicus, a circum-umbilical incision with the ports placed at the 3 corners of the incision provided the best triangulation and minimum clashing rather than placing the initial port through the umbilicus. Dissection of the Calot's was made easier with the use of the right-angled dissector. However, since there was no suture taken in the gall bladder to assist retraction, dissection of the gall bladder of the liver bed became more difficult for long and floppy gall bladders. The medial dissection in the Calot's triangle was made easier using a crossed-hands approach; however, this part of the operation remained technically challenging. Suture retraction of the gall bladder has been widely used and there have been no reports of increased complications due to bile peritonitis. We found that retraction of the gall bladder was possible without sutures if the patient was not too tall. Recently there has been an interest in using magnetic retractors that allow retraction of the gall bladder from outside the abdominal cavity using magnetic forceps. This may provide better retraction without fear of perforation, although the costs may increase.

The shape of the skin incision changed over the course of time. Initially, we used an incision through the centre of the umbilicus. We then moved on to using a circumferential incision on the umbilicus leaving a skin rim at the superior aspect. The post-operative cosmetic result was excellent with the scar disappearing into the umbilicus in most cases.

Apart from cosmesis, the hypothesized advantages of SIL have been less pain, decreased analgesic requirement and shorter hospital stay. Some studies have shown decreased analgesic requirement and others have suggested reduced pain at 8 hours post-operatively, most studies do not report a significant difference between SIL and CL in these respects. In our series, there was no difference in hospital stay for patients who underwent SIL. Since we did not randomize patients to either surgery, we could not accurately measure the differences in pain, hospital stay and return to work, but there was no appreciable difference that we noted.

There has been a concern that multiple ports may lead to an increased incidence of incisional hernia due to increased stress on the sheath and the difficulty of closing multiple fascial incisions close together. In our series, after follow-up of 4 years, there was no reported incidence of incisional hernia.

The main difficulties with single incision surgery are the technical difficulty and the increased cost. While the procedure is technically more demanding than a standard laparoscopic cholecystectomy, it has been shown that the learning curve is not too long for trained laparoscopic surgeons. We found that with patience and careful dissection, the technical difficulties of the procedure can be overcome. We also found that by using standard instruments, the cost of SIL could be significantly lowered and the only increased cost came from the increased theatre time for the procedure. However, this is to be expected in the learning period and while even in 
large series, there was a significant difference in the operative time, times as low as 25 minutes for SIL compared to 18 minutes for CL have been reported.

\section{CONCLUSION}

With more and more surgeons beginning to innovate new procedures of SIL, it is becoming clear that the procedure is here to stay. We have found that SIL is a safe procedure that can be offered even in secondary level hospitals at no increased cost, using standard instruments. Surgeons should ideally attempt SIL only after achieving competency in 3-port cholecystectomy. A careful case selection is essential for safety during the learning curve with immediate conversion in case of adhesions, difficult anatomy or unsuitable body habitus. Demonstration of the critical view of safety is crucial for preventing bile duct injury. With the use of standard equipment the costs of SIL can be brought down to the same level as a while providing an excellent cosmetic result. Patience and adherence to the basic principles of safe surgery will allow competent laparoscopic surgeons to safely perform single incision laparoscopic cholecystectomy even in resource-poor settings.

Funding: No funding sources

Conflict of interest: None declared

Ethical approval: The study was approved by the institutional ethics committee

\section{REFERENCES}

1. Navarra G, Pozza E, Occhionorelli S, Carcoforo P, Donini I. One-wound laparoscopic cholecystectomy. Br J Surg. 1997;84:695.

2. Bhandarkar D, Mittal G, Shah R, Katara A, Udwadia TE. Single-incision laparoscopic cholecystectomy: How I do it? Journal of Minimal Access Surgery. 2011;7(1):17-23.
3. Love KM, Durham CA, Meara MP, Mays AC, Bower CE. Single-incision laparoscopic cholecystectomy: a cost comparison. Surg Endosc. 2011;25(5):1553-8.

4. Rivas H, Varela E, Scott D. Single-incision laparoscopic cholecystectomy: initial evaluation of a large series of patients. Surg Endosc. 2010;24(6):1403-12.

5. Antoniou SA, Pointner R, Granderath FA. Singleincision laparoscopic cholecystectomy; a systematic review. Surg Endosc. 2010;25:367-7.

6. Han HJ, Choi SB, Kim WB, Choi SY. Singleincision multiport laparoscopic cholecystectomy: things to overcome. Arch Surg. 2011;146(1):68-73.

7. Dominguez G, Durand L, De Rosa J, Danguise E, Arozamena C, Ferraina PA. Retraction and triangulation with neodymium magnetic forceps for single-port laparoscopic cholecystectomy. Surg Endosc. 2009;23:1660-6.

8. Khambaty F, Brody F, Vaziri K, Edwards C. Laparoscopic versus single-incision cholecystectomy. World J Surg. 2011;35(5):967-72.

9. Prasad A, Mukherjee KA, Kaul S, Kaur M. Postoperative pain after cholecystectomy: Conventional laparoscopy versus single-incision laparoscopic surgery. Journal of Minimal Access Surgery. 2011;7(1):24-7.

10. Solomon D, Bell R, Duffy A, Roberts K. Singleport cholecystectomy: small scar, short learning curve. Surg Endosc. 2010;24:2954-7.

11. Sinha R, Yadav AS. Transumbilical single incision laparoscopic cholecystectomy with conventional instruments: A continuing study. Journal of Minimal Access Surgery. 2014;10(4):175-9.

12. Sinha R. Transumbilical single- incision laparoscopic cholecystectomy with conventional instruments and ports: the way forward? J Laparoendosc Adv Surg Tech A. 2011;21(6):497503.

Cite this article as: Mathew A, Wanshnong L, Wann C. Single-incision laparoscopic cholecystectomy in a resource-poor setting: Improving safety during the learning curve. Int Surg J 2016;3:249-52. 